\title{
Children's Exposure to Violence in the Family and Community
}

\author{
Gayla Margolin and Elana B. Gordis \\ University of Southern California
}

\begin{abstract}
Exposure to family and community violence is linked with aggression, depression, posttraumatic stress symptoms, and academic and cognitive difficulties. It has the potential to permeate many dimensions of children's day-to-day lives and to erode possible sources of social support. Although the literature focuses on deleterious outcomes, many children fare well in the face of exposure to violence. Research attending to developmental processes, the co-occurrence of multiple forms of violence, and psychobiological mechanisms will clarify why outcomes are better for some children than for others. Greater understanding of children's risk and resilience in the face of such exposure will inform intervention efforts.
\end{abstract}

KEYWORDS_children; child abuse; interparental violence; community violence; risk and resilience

Violence is a public-health problem, and children are particularly vulnerable to its effects. Besides being a leading source of injury, violence takes a toll on more subtle aspects of functioning, such as cognitive, behavioral, social, and emotional functioning. Disruption in these domains can affect children's progression through typical developmental processes, with the nature of the impact dependent on the timing, type, and chronicity of the exposure to violence. Violence affects children even if they are not the direct victim but have a close relationship with the victim.

Because exposure to violence typically occurs in familiar settings, the safe havens of family and community are marred by danger. Parents have not been able to prevent the violence and may be the perpetrators, the victims, or themselves affected in ways that compromise their caretaking. Distressing consequences of violence may include breakup or relocation of the family or repercussions following disclosure of abuse. Children living with violence may also experience family conflict and other life stresses, such as poverty, parents' unemployment, or parents' substance abuse and psychopathology. In an iterative fashion, these life stresses increase the risk for continued violence, and violence increases the likelihood of these stresses.

Address correspondence to Gayla Margolin, University of Southern California, Department of Psychology, SGM 930, Los Angeles, CA 90089-1061; e-mail: margolin@usc.edu.

\section{SCOPE OF CHILDREN'S EXPOSURE TO VIOLENCE}

\section{Definitions}

Violence is defined in many different ways in the research on its effects on children. Major categories of violence that have been investigated are (a) child maltreatment, including physical abuse, sexual abuse, and neglect; (b) aggression between parents; and (c) community violence, including direct victimization and witnessing of violence. Despite high rates of co-occurrence among exposure to different types of violence (Appel \& Holden, 1998; Margolin \& Gordis, 2000), published works have typically examined child abuse, domestic violence, and community violence separately.

A key issue is the wide range of severity in the violence that children observe or experience. Some forms of severe aggression, such as beatings or use of weapons, can be traumatic to the victim and to observers. Other forms of aggression, such as pushing or shoving and corporal punishment, are considered normative by much of society. In samples drawn from the population at large, low-severity aggressive behaviors may suffice as the criterion for violence. Other studies compare people recruited from shelters, treatments, or child protective services who have been exposed to violence with people who have not received such services. In these studies, the violence-exposed groups typically have experienced severe, injurious behaviors. However, lower-severity aggressive behaviors may have occurred in both groups.

\section{Rates of Exposure}

Estimates of the rate of children's exposure to violence vary because of different definitions and methods of data collection. Using official and unofficial reports of professionals working with children, The National Center of Child Abuse and Neglect (NCCAN) estimated that approximately 23 per 1,000 children are victims of maltreatment, including physical abuse, sexual abuse, and neglect (Sedlack \& Broadhurst, 1996). Rates of severe physical abuse, based on national studies of the population at large, are 49 per 1,000, or five times the NCCAN estimate (Straus, Hamby, Finkelhor, Moore, \& Runyan, 1998). Straus (1992) extrapolated that each year more than 10 million U.S. children witness physical aggression between their parents. Rates of community violence are generally based on interviews or surveys with children and sometimes corroborated by parents. Richters and Martinez (1993) reported that exposure to community violence is quite common, with at least one third of children victimized and more than $90 \%$ witnessing violence at least once during their 
childhoods. With the majority of children having some type of violence exposure, researchers need to distinguish between severe and mild exposure and between chronic and one-time events.

\section{EFFECTS OF EXPOSURE TO VIOLENCE}

\section{Short-Term Effects}

Although each type of violence has its own literature, studies have shown some common short-term effects. (For a detailed review of the effects of family and community violence, see Margolin \& Gordis, 2000.) Children who are exposed to violence of any kind may exhibit behavioral disorders such as aggression and delinquency; emotional and mood disorders such as depression and anxiety; posttraumatic stress symptoms such as exaggerated startle, nightmares, and flashbacks; health-related problems and somatic symptoms such as sleep disturbances; and academic and cognitive problems. Some forms of violence tend to have specific consequences. For example, sexual acting out sometimes is a specific consequence of sexual abuse. However, exposure to other forms of violence also may lead to this problem, but the connections are not as theoretically salient, and not all of the connections have been investigated.

Exposure to family and community violence is linked with aggressive behavior. One of the theoretical perspectives that explains this link is social learning theory, according to which children learn from the aggressive models in their environments. Additionally, victimization may compromise children's ability to regulate their emotions, and as a result they may act out aggressively. Sexual abuse, physical abuse, and exposure to violence between parents and in the community have all been linked to aggression, with links particularly well documented for physical abuse.

Considerable literature documents links between exposure to violence and problems such as depression and anxiety. A child may interpret violence at home and in the community to mean that the world is unsafe and that he or she is unworthy of protection. This interpretation may engender helplessness and lead to negative selfperceptions. Community violence also is linked to anxiety and depression, though one methodological issue is that studies of community violence frequently include intrafamilial as well as extrafamilial violence.

Posttraumatic stress symptoms and posttraumatic stress disorder (PTSD) are important consequences of exposure to violence because they can impair social and behavioral functioning. Many children who do not meet diagnostic criteria for PTSD may experience troublesome symptoms. Physical and sexual abuse, community violence, and exposure to domestic violence are linked with posttraumatic stress symptoms, with links particularly well documented for sexual abuse. The degree to which exposure leads to posttraumatic stress symptoms in children may vary with the intensity of the violence and the degree to which the violence has lasting effects on the people most important to them (e.g., witnessing a stranger being punched vs. seeing a parent being assaulted vs. being directly victimized).

Family violence and community violence also relate to academic and cognitive difficulties, possibly through their impact on psychological functioning. For example, PTSD and depression may interfere with learning and with the ability to perform well in the classroom. Neglect has a particularly negative impact on academic and cognitive performance.

\section{Long-Term Effects}

A few prospective studies in this area have explored whether exposure to violence during childhood increases the likelihood of either perpetrating or being the victim of aggression during adulthood. In a 20year prospective study by Ehrensaft et al. (2003), children who were exposed to violence between their parents subsequently were more likely to perpetrate violence against an adult partner and to be treated violently by an adult partner than were children who were not exposed to violence; children who were physically abused had an increased rate of injuring a partner. However, Kaufman and Zigler's (1987) early review of prospective studies concluded that although a history of abuse increases the rate of abuse toward children from $5 \%$ to approximately $30 \%, 70 \%$ of children exposed to violence do not become abusive adults. Moreover, Widom (1998) concluded that childhood victimization increases the risk of criminal behavior and other mental health problems, but the "cycle of violence is not deterministic or inevitable" (p. 226).

\section{KEY DIRECTIONS FOR RESEARCH}

The variability across children in the effects of exposure to violence is largely unexplained. Many children do not exhibit negative outcomes at the time they are studied. For example, using meta-analytic procedures to combine statistically the results of 118 studies on children's exposure to domestic violence, Kitzmann, Gaylord, Holt, and Kenny (2003) found that $63 \%$ of child witnesses to violence were doing worse than nonwitnesses, whereas $37 \%$ were doing comparably or better.

The fundamental question remains: Why do some children show negative outcomes and other children appear to be more resilient? Although early research primarily examined the outcomes associated with violence, research recently has begun to explore the mechanisms that explain these outcomes.

\section{Developmental Processes}

An important consideration is how exposure to violence alters the typical developmental course. For example, risk taking typically increases in adolescence, but studies need to examine whether risk taking differs between teenagers who have and have not been exposed to violence. It is possible, for instance, that exposure to violence is associated with increased, prolonged, or earlier onset of risk taking. Moreover, researchers need to identify the developmental processes underlying linkages between exposure to violence and later developmental problems. If the short-term effects are exhibited in emotional dysregulation, cognitive difficulties, and disruptions in important relationships with caregivers, these effects may increase risk for subsequent failure in two key developmental tasks: establishing a supportive peer network and effective work habits at school. Disruption of these tasks places the adolescent at risk for further problems, including school failure, depression, involvement with deviant peers, substance abuse, and delinquent behaviors.

A developmental perspective highlights the following types of questions: Does early exposure to violence trigger more profound disruption in development than later exposure? Does exposure have delayed effects, and do delayed effects occur regardless of whether the exposure continues? The study of developmental processes could 
identify developmental periods of particular vulnerability, as well as periods amenable for intervention.

In addition to having direct effects, exposure to violence compromises interpersonal relationships that are the fabric of children's daily lives. Social support is a key buffer against the negative effects of violence. Because parents are key sources of social support, the disrupted parenting associated with family violence may exacerbate negative effects of exposure to violence (Margolin, Gordis, \& Oliver, in press). More generally, children exposed to violence may be sensitized to hostile interactions and may have difficulty negotiating peer conflicts. These interpersonal difficulties can rob children of social support and increase their risk for associating with deviant peers.

Exposure to Multiple Forms of Violence

Research findings have not yet clarified whether exposure to multiple types of violence increases the risk of negative effects (Kitzmann et al., 2003). Exposure to multiple types of violence may increase risk because it tends to be associated with a higher frequency of exposure and increased seriousness of violence. Alternatively, exposure to multiple forms of violence may increase risk because it reflects severe disruptions in parent-child relations, particularly if the child both witnesses aggression between his or her parents and is directly maltreated.

Moreover, children who both observe aggression between their parents and are directly victimized may perceive aggression and conflict as particularly threatening, and consequently develop difficulty regulating their own emotions and hypervigilance to cues associated with interpersonal conflict. We (Gordis, Margolin, \& John, 1997) found that parent-to-child hostility exacerbated the effects of aggression between parents on children's distress during family discussions. Investigators need to explore whether children become more reactive to aggression when they both observe it in their parents and are themselves directly victimized.

Because families are made up of interconnected subsystems (e.g., marital, parent-child), violence in one family subsystem can spill over into other family subsystems. Although personality and genetic factors can predispose someone to behave aggressively with multiple family members, a family systems perspective suggests that one type of violence exposure can overwhelm a family system, deplete emotional and physical resources, and lower thresholds for aggression in other family subsystems. We (Margolin \& Gordis, 2003) found that an accumulation of aversive family circumstances, such as high financial stress and high parenting stress, renders families vulnerable to aggression across multiple subsystems. Additional research is needed to identify factors that allow conflicts and aggression to spread from one family subsystem to another.

\section{Psychobiological Approaches}

An important recent development is the focus on both biological and psychological consequences of exposure to violence (e.g., De Bellis, 2001). Children who have been exposed to violence may experience dysregulation of the hypothalamic-pituitary-adrenal (HPA) axis, the stress response system. This system involves the release of a series of hormones, resulting in the secretion of cortisol from the adrenal glands. Researchers have found links between exposure to violence and levels of cortisol both in nonstressful situations and in response to a stressor. However, the direction of dysregulation is inconsistent, with research showing both higher and lower cortisol levels in children exposed to violence. The variability of findings may reflect different types of response to stress. Emerging research additionally suggests that different types of dysregulation of the HPA axis may correspond to different types of behavioral problems in children. Much remains unknown about this complex and important stress-response system.

Exposure to violence may also cause disturbances in physical and sexual development. Stress may lead to elevations in certain gonadal hormones. Some researchers suggest that these effects may result in the early onset of puberty and elevated levels of sexual behavior often linked to sexual abuse. Moreover, factors associated with increased sympathetic nervous system activity (the "fight or flight" response), including hormone and catecholamine neurotransmitter activity, appear to suppress immune function and may even damage brain cells in the hippocampus, which is important in memory functioning. Researchers also have found alterations in patterns of growth hormone response in abused children. These disturbances may cause disturbances in patterns of physical growth.

Another new research direction is the application of twin studies to examine the effects of violence exposure. A nagging concern with earlier literature on exposure to violence is that genetic links may account for outcomes assumed to be environmentally influenced. However, researchers recently have found that exposure to family violence contributes over and above the effects of genetic influences to various outcomes, such as IQ (e.g., Koenen, Moffitt, Caspi, Taylor, \& Purcell, 2003). Thus, accumulating evidence indicates that exposure to violence has an effect on behavior that goes beyond the effects of shared genes.

Many questions remain for psychobiological research. What is the normal developmental course of relevant biological systems, and how are these systems altered by exposure to violence? How do these systems relate to maladaptive emotional and behavioral functioning? Most important, what aspects of the psychobiological variables are amenable to interventions that would improve outcomes, and how can psychobiological consequences of exposure to violence inform treatments for violence-exposed children?

\section{CONCLUSION}

Data repeatedly indicate that exposure to family and community violence compromises the development of some but not all children. Explanatory models of individual and contextual factors that either buffer against or exacerbate the effects of violence are needed. Individual factors for these models include cognitive, behavioral, emotional, and biological resources available to the child. Relevant contextual dimensions include family, community, and cultural factors that influence children's interpretation of and reactions to violence.

Although previous research has emphasized what is wrong with children who have been exposed to violence, a focus on children's successful adaptation is equally important. Resilience to such exposure is a function of how children manage and cut short negative chain reactions, for example, through effective problem solving, supportive responses from family or peers, and opportunities for success at school. Resilience, however, is not a fixed characteristic, but changes across time and circumstances. Protective factors may be more accessible to children as they mature; alternatively, chronic exposure to violence or exposure to severe violence may erode protective factors. 
Children's exposure to violence frequently goes unnoticed and unattended by parents and by professionals who work with children. Parents typically underestimate their children's exposure to violence and may even be unaware of abuse in the home. Children exposed to violence tend to exhibit symptoms associated with common types of maladjustment. Thus, professionals may not be aware when violence plays a role in the etiology of those symptoms. Detailed information about the range of consequences related to exposure to violence and the factors that influence those consequences will help to identify children who may be at risk for negative outcomes. Moreover, little is known about whether standard treatments for childhood disorders are effective in the context of exposure to violence. Models for understanding risk and protective factors in the child and his or her social context will inform interventions for violence-exposed children.

\section{Recommended Reading}

Cicchetti, D., \& Toth, S. (1995). A developmental psychopathology perspective to child abuse and neglect. Journal of the American Academy of Child and Adolescent Psychiatry, 34, 541-564.

Cicchetti, D., \& Toth, S. (1997). Rochester Symposium on Developmental Psychopathology: Developmental perspectives on trauma: Theory, research, and intervention. Rochester, NY: University of Rochester Press.

Margolin, G., \& Gordis, E.B. (2000). (See References)

Repetti, R.L., Taylor, S.E., \& Seeman, T.E. (2002). Risky families: Family social environments and the mental and physical health of offspring. Psychological Bulletin, 128, 330-366.

Trickett, P.K., \& Schellenback, C.J. (1998). Violence against children in the family and the community. Washington, DC: American Psychological Association.

Acknowledgments-Preparation of this article was supported by Grant 99-8412 from the David and Lucile Packard Foundation and by National Institutes of Health Grant K23HD041428.

\section{REFERENCES}

Appel, A.E., \& Holden, G.W. (1998). The co-occurrence of spouse and physical child abuse: A review and appraisal. Journal of Family Psychology, 12, 578-599.
De Bellis, M.D. (2001). Developmental traumatology: The psychobiological development of maltreated children and its implications for research, treatment, and policy. Development and Psychopathology, 13, 539-564.

Ehrensaft, M.K., Cohen, P., Brown, J., Smailes, E., Chen, H., \& Johnson, J.G. (2003). Intergenerational transmission of partner violence: A 20-year prospective study. Journal of Consulting and Clinical Psychology, 71, 741-753.

Gordis, E.B., Margolin, G., \& John, R.S. (1997). Marital aggression, observed parental hostility, and child behavior during triadic family interaction. Journal of Family Psychology, 11, 76-89.

Kaufman, J., \& Zigler, E. (1987). Do abused children become abusive parents? American Journal of Orthopsychiatry, 57, 186-192.

Kitzmann, K.M., Gaylord, N.K., Holt, A.R., \& Kenny, E.D. (2003). Child witnesses to domestic violence: A meta-analytic review. Journal of Consulting and Clinical Psychology, 71, 339-352.

Koenen, K.C., Moffitt, T.E., Caspi, A., Taylor, A., \& Purcell, S. (2003). Domestic violence is associated with environmental suppression of IQ in young children. Development and Psychopathology, 15, 297-311.

Margolin, G., \& Gordis, E.B. (2000). The effects of family and community violence on children. Annual Review of Psychology, 51, 445-479.

Margolin, G., \& Gordis, E.B. (2003). Co-occurrence between marital aggression and parents' child abuse potential: The impact of cumulative stress. $\mathrm{Vi}$ olence and Victims, 18, 243-258.

Margolin, G., Gordis, E.B., \& Oliver, P. (in press). Links between marital and parent-child interactions: Moderating role of husband-to-wife aggression. Development and Psychopathology.

Richters, J.E., \& Martinez, P. (1993). The NIMH Community Violence Project: I. Children as victims of and witnesses to violence. In D. Reiss, J.E. Richters, M. Radke-Yarrow, \& D. Scharff (Eds.), Children and violence (pp. 7-21). New York: Guilford.

Sedlack, A.J., \& Broadhurst, D.D. (1996). Third National Incidence Study of Child Abuse and Neglect. Washington, DC: U.S. Department of Health and Human Services, National Center of Child Abuse and Neglect.

Straus, M.A. (1992). Children as witnesses to marital violence: A risk factor of lifelong problems among a nationally representative sample of American men and women. In D.F. Schwarz (Ed.), Children and violence: Report of the Twenty-Third Ross Roundtable on Critical Approaches to Common Pediatric Problems (pp. 98-109). Columbus, OH: Ross Laboratories.

Straus, M.A., Hamby, S.L., Finkelhor, D., Moore, D.W., \& Runyan, D. (1998). Identification of child maltreatment with the Parent-Child Conflict Tactics Scales: Development and psychometric data for a national sample of American parents. Child Abuse and Neglect, 22, 249-270.

Widom, C.S. (1998). Child victims: Searching for opportunities to break the cycle of violence. Applied \& Preventive Psychology, 7, 225-234. 